\title{
Growth-phase-dependent transcriptional regulation of the pcm and surE genes required for stationary-phase survival of Escherichia coli
}

\author{
Chuan Li, ${ }^{1}$ Pei-Ying $\mathrm{Wu}^{2}$ and Mingli Hsieh ${ }^{1}$ \\ Author for correspondence: Chuan Li. Tel: +88643896190 ext 50617. Fax: +88643892412. \\ e-mail: cli@mercury.csmc.edu.tw
}

Institute of Medicine ${ }^{1}$ and School of Medical Technology2, Chung-Shan Medical and Dental College, 110, Section 1 Chein-Kuo North Road, Taichung, Taiwan

\begin{abstract}
Two neighbouring genes, surE and pcm, at $59 \mathrm{~min}$ on the Escherichia coli chromosome are both required for stationary-phase survival. Operon fusions of the putative promoter regions in front of surE (P2) or Pcm (P3) with the lacz reporter gene were constructed to study the transcriptional regulation of $\mathrm{pcm}$ and surE. Both promoter regions were able to activate $\beta$-galactosidase activity in a growth-phase-dependent way in either rich or minimal medium. Induction from both promoters reached the highest level in late stationary phase and was independent of the rpos/katF gene. Spent medium from early as well as late stationary-phase cultures could induce the expression of either promoter even after dialysis or boiling. A high cell density could induce the promoters more rapidly but not to a greater extent. It is proposed that the induction might be correlated with the decline in growth rate of the cells. The induction patterns of either $\mathrm{P2}$ or $\mathrm{P3}$ were very similar. pcm can thus be transcribed from both the P2 and P3 promoters that are regulated in similar ways.
\end{abstract}

Keywords: operon fusion, stationary-phase survival, protein carboxyl methyltransferase

\section{INTRODUCTION}

A protein-L-isoaspartyl O-methyltransferase (EC 2.1.1.77) can specifically catalyse the transfer of the methyl groups from $S$-adenosylmethionine to atypical Lisoaspartyl but not normal L-aspartyl residues in proteins (Clarke, 1985). The wide distribution of the activity of this methyltransferase in the living world from eubacteria (Fu et al., 1991; Li \& Clarke, 1992a) to fungi (Johnson et al., 1991), worms (Kagan \& Clarke, 1995), plants (Mudgett \& Clarke, 1993) and mammals (Ingrosso et al., 1989; O'Connor \& Clarke, 1985), and the conservation of the amino acid sequence of the enzyme between species (e.g. $31 \%$ identity between human and Escherichia coli), indicate a house-keeping role of the enzyme (Fu et al., 1991; Ingrosso et al., 1989). Proteins or peptides with abnormal aspartyl residues derived from spontaneous protein degradation (Harding et al., 1989; Stadtman, 1988) are less reactive (Brennan et al., 1994; Johnson et al., 1987). Since methylation of the L-isoaspartyl residues facilitates the conversion of these residues to the normal form, it has been proposed that the methyltransferase might help to repair damaged

Abbreviation: $\mathrm{Pcm}$, protein carboxyl methyltransferase. proteins that can accumulate with time (Johnson et al., 1987; McFadden \& Clarke, 1982, 1987). E. coli mutant strains without the $p \mathrm{~cm}$ gene (encoding protein carboxyl methyltransferase, $\mathrm{Pcm}$ ) exhibit reduced stationaryphase survival and heat resistance (Li \& Clarke, 1992b). These phenotypes are consistent with the hypothesis that the enzyme is involved in the metabolism of $\mathrm{L}$ isoaspartyl-containing proteins that can accumulate.

pcm is located at $59 \mathrm{~min}$ on the E. coli chromosome (Fu et al., 1991). Another gene, surE, that is also involved in the stationary-phase survival of E. coli is directly upstream of $p c m$ (Li et al., 1994). Survival of Gramnegative bacteria in stationary-phase or nutrient-limited cultures that more closely resemble the conditions in the natural habitats of these organisms has been intensively studied (Kolter et al., 1993; Matin et al., 1989; Roszak $\&$ Colwell, 1987). An alternative $\sigma$ factor, $\sigma^{s}$, encoded by the $r p o S / k a t F$ gene plays a central regulatory role in stationary-phase survival or survival under other stress conditions such as osmotic pressure (Hengge-Aronis, 1993; Lange \& Hengge-Aronis, 1991; Loewen \& Hengge-Aronis, 1994). The rpoS gene product is a transcription factor essential for the induction of some stationary-phase survival genes during the transition from exponential- to stationary-phase growth (Loewen 
Table 1. Bacterial strains, plasmids and phages

\begin{tabular}{|c|c|c|}
\hline Strain/plasmid/phage & Description & Source/reference \\
\hline \multicolumn{3}{|l|}{ E. coli } \\
\hline MC4100 & $\begin{array}{l}\mathrm{F}^{-} \Delta(\arg F-\text { lac }) U 169 \text { araD139 rpsL150 ptsF } 25 \\
\text { fbB5301 rbsR deoC relA1 }\end{array}$ & Lange \& Hengge-Aronis (1991) \\
\hline RH90 & MC4100 rpoS359:: Tn10 & Lange \& Hengge-Aronis (1991) \\
\hline CL415-2 & MC4100(iCL415-2) & This study \\
\hline CL415-3 & MC4100( $(\mathrm{CL} 415-3)$ & This study \\
\hline CL415-2R & $\mathrm{RH} 90(\lambda \mathrm{CL} 415-2)$ & This study \\
\hline CL415-3R & RH90(iCL415-3) & This study \\
\hline \multicolumn{3}{|l|}{ Plasmids } \\
\hline pRS415 & Operon fusion vector & Simons et al. (1987) \\
\hline pHJK5-2 & EcoRI-BamHI surEp (P2) fragment in pRS415 & This study \\
\hline pHJK5-3 & EcoRI-BamHI pcmp (P3) fragment in pRS415 & This study \\
\hline pCL1 & $\begin{array}{l}\text { Re-ligation of a } 7.5 \mathrm{~kb} \text { EcoRI-SnaBI fragment } \\
\text { from pMMkatF1 }\end{array}$ & Li \& Clarke (1992b) \\
\hline pCL2 & $\begin{array}{l}4.5 \mathrm{~kb} \mathrm{BamHI}-B s p \mathrm{HI} \text { fragment from pMMkatF1 } \\
\text { inserted in the Bam } \mathrm{HI}-S m a \mathrm{I} \text { site of pGEM-7Zf }+\end{array}$ & Li et al. (1994) \\
\hline \multicolumn{3}{|c|}{${ }^{2}$} \\
\hline iRS45 & Operon fusion phage vector & Simons et al. (1987) \\
\hline$\lambda \mathrm{CL} 415-2$ & iRS45 with $\phi$ (surEp-lacZ) operon fusion & This study \\
\hline ¿CL415-3 & $\lambda \mathrm{RS} 45$ with $\phi(p c m p-l a c Z)$ operon fusion & This study \\
\hline
\end{tabular}

\& Hengge-Aronis, 1994; Weichart et al., 1993). Whether $p c m$ is regulated by $r p o S$ is not clear, although it is interesting that $p c m$ is only separated by one gene (nlpD) from $r p o S$ on the E. coli chromosome (Ichikawa et al., 1994) and this region appears to be important for stationary-phase survival.

It has been shown that the activity of Pcm can be induced 1.7-fold on transition from exponentialstationary-phase growth (Li \& Clarke, 1992b). How the expression of $p \mathrm{~cm}$ is regulated by the growth state and/or environmental factors is not clear. Reasonable promoter segments immediately upstream of $\mathrm{pcm}$ cannot be identified by comparison with consensus promoter sequences. A putative promoter (designated P2; Li et al., 1994) that is about $1.2 \mathrm{~kb}$ upstream of $p c m$ was found to be the closest to $p \mathrm{~cm}$ with the best match to consensus $E$. coli RNA polymerase recognition sequences. Primer extension analysis of the $5^{\prime}$ terminus revealed a $G$ residue as a single start site 6 bases downstream of the proposed -10 region of the putative P2 promoter (Li et al., 1994). Expression of surE immediately downstream of this promoter has been shown by coupled in vitro transcription/translation (Li et al., 1994). Since surE is immediately upstream of $p \mathrm{~cm}$ and both cistrons overlap by $4 \mathrm{bp}$, it is very likely that they are in the same operon and that this promoter region is responsible for the transcription of both surE and $p c m$ (Li et al., 1994). RNA species containing elements of both the surE and $p c m$ genes have been revealed by reverse transcriptase (RT)-PCR experiments, supporting the existence of the surE-pcm operon (Li et al., 1994). Nevertheless, a surE mutant strain, CL2010, with a kanamycin resistance cassette inserted at a BstEII site in the middle of surE in the opposite direction to $p \mathrm{~cm}$, expressed $18 \%$ Pcm activity compared to that of wild-type cells. Thus, expression of $p \mathrm{~cm}$ in CL2010 is unlikely to be under the control of P2 ( $\mathrm{Li} \&$ Clarke, 1992b). Another promoter (designated P3) located directly in front of $p \mathrm{~cm}$ might be responsible for Pcm activity even though no good promoter can be identified in this region by sequence comparison. In this investigation we constructed operon fusions of both putative promoter regions in front of surE and $p \mathrm{~cm}$ (see Fig. 1) with the lac $Z$ gene to study the regulation of the expression of both genes at the transcription level.

\section{METHODS}

Bacterial strains, plasmids, phages and growth conditions. The genotypes of the E. coli strains, plasmids and bacteriophages utilized in this study are listed in Table 1 . Bacteria were grown with aeration in glass tubes or flasks at $37^{\circ} \mathrm{C}$ unless otherwise indicated. LB (Difco) or M9 medium (with $0.2 \%$ glucose as carbon source) were prepared as described by Miller (1992). When required, ampicillin and X-Gal were added to the medium at concentrations of 100 and $40 \mu \mathrm{g} \mathrm{ml}^{-1}$, respectively.

Construction of lacZ operon fusion plasmids. Using PCR, we prepared segments of putative promoter DNA [P2 (surEp) in front of surE, and P3 ( $p c m p)$, the possible promoter region in front of $p c m$; Fig. 1] flanked by $5^{\prime} E c o$ RI and 3' BamHI sites so that they could be directly inserted into the operon fusion vector pRS415 (Table 1, Simons et al., 1987) in front of the lacZ gene. The primers used for PCR were P2L (5' GTACCGAAtTcCTTCGGTGCCCAACG, corresponding to $\mathrm{nt}$ 1258-1283 in Li et al., 1994), P2R (5' CGCTGgGaTCC CATTCGCCACTGCCTG, complementary to nt 1571-1597 in $\mathrm{Li}$ et al., 1994), P3L (5' GTCCGGAATTcACGCCGGGCCGAATC, corresponding to nt 2088-2113 in Li et al., 1994) and P3R (5' GAACCGGatCCAATTTCCAGCAC- 


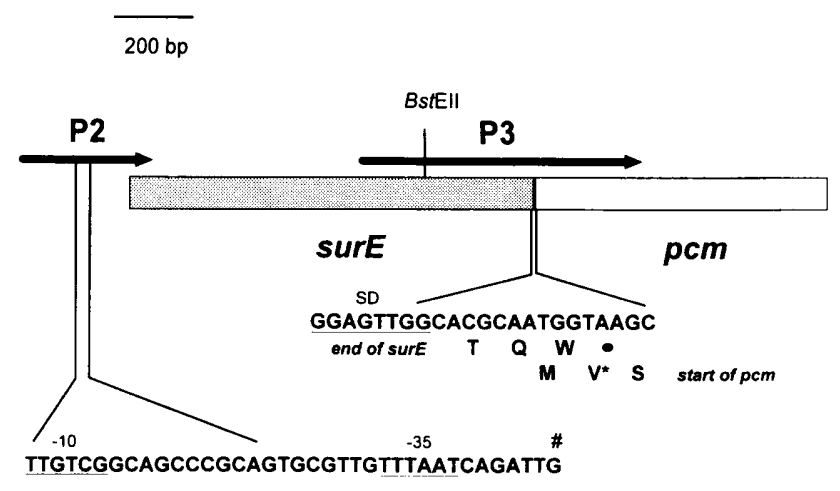

Fig. 1. Illustration of the position of the $P 2$ and $P 3$ regions used in the lac $Z$ fusion constructs. The sequence of the identified -35 and -10 regions of $P 2$ (Li et al., 1994) and the potential Shine-Dalgarno ribosomal initiator sequence of $\mathrm{pcm}$ (Fu et al., 1991) are underlined. The transcriptional start site of surE is marked by \#. The overlap of surE and pcm is shown. The valinyl residue marked by * is the $\mathrm{N}$-terminal residue determined by sequence analysis of the purified $E$. coli L-isoaspartyl methyltransferase (Fu et al., 1991).

CCG, complementary to $\mathrm{nt}+232-257$ in Fu et al., 1991). Restriction sites for EcoRI and BamHI are underlined and the bases that have been changed are indicated in lower case letters. For each reaction, $10 \mathrm{nmol}$ primers, $200 \mathrm{ng}$ template DNA (pCL1), 2.5 U Taq DNA polymerase (Promega) and $20 \mathrm{nmol}$ each of the four dNTPs were included in a final volume of $100 \mu \mathrm{l}$ with $2.5 \mathrm{mM} \mathrm{MgCl}$ in standard Taq

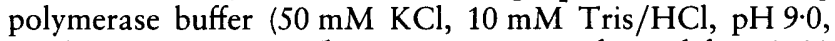
$0.1 \%$ Triton X-100). The reaction was performed for $10-20$ cycles of $30 \mathrm{~s}$ at $95^{\circ} \mathrm{C}$ (first cycle, $4 \mathrm{~min}$ ), $30 \mathrm{~s}$ at $60^{\circ} \mathrm{C}$ and $30 \mathrm{~s}$ at $75{ }^{\circ} \mathrm{C}$ (final cycle, $3 \mathrm{~min}$ ). The reaction products were extracted by chloroform, digested with EcoRI and BamHI and then ligated to pRS415 that had also been digested with EcoRI and BamHI. Plasmids pHJK5-2 and pHJK5-3, containing the successful P2 and P3 promoter-lacZ fusion constructs, respectively, were confirmed by restriction digestion and DNA sequence analysis and were further used to transform a $\triangle l a c Z$ strain, MC4100 (Table 1).

Transferring the lacZ operon fusions from plasmids to chromosomes. Phage $\lambda \mathrm{RS} 45$ (Table 1 ) was used to transfect MC4100 cells harbouring plasmid pHJK5-2 or pHJK5-3, according to the protocols of Simons et al. (1987), to move the promoter-lac $Z$ constructs into the phage. High titre stocks of the resulting recombinant phages, $\lambda$ CL415-2 or $\lambda$ CL415-3, were used to transfect $E$. coli $M C 4100$ or a $\sigma^{\mathrm{s}}$-deficient strain, RH90 (Lange \& Hengge-Aronis, 1991). Successful blue lysogens on X-Gal/LB plates were used for further studies.

$\boldsymbol{\beta}$-Galactosidase assay. $\beta$-Galactosidase activities were determined with chloroform/SDS-permeablilized cells using ONPG (Sigma) as substrate using the protocol described by Miller (1992). $\beta$-Galactosidase activity is expressed in Miller units. Each value was the mean of two independent assays.

\section{RESULTS}

\section{Transcription can be initiated by either $\mathrm{P} 2$ or $\mathrm{P3}$}

Putative promoters P2 (surEp) or P3 ( $p c m p)$ were fused in front of the reporter lacZ gene in the multicopy operon fusion vector pRS415 to form operon fusion plasmids $\mathrm{pHJK5}-2$ and $\mathrm{pHJK5}-3$, respectively (Table
1). The strength of these putative promoter regions was determined by measuring $\beta$-galactosidase activity in MC4100 ( $\Delta l a c Z)$ cells transformed with the operon fusion plasmids. Both promoters appeared to be good promoters and could be induced both in growing cells and in cells approaching stationary phase (data not shown). However, the results were not consistent when cells entered stationary phase. In view of the fact that the copy number of the plasmids carrying the reporter fusions might vary as cells entered stationary phase and thus interfere with the results, we further transferred the fusions to the E. coli chromosome using recombinant phages to eliminate the copy number problem. The resulting lysogens, CL415-2 and CL415-3, contained $\mathrm{P} 2-$ lacZ or P3-lacZ fusions, respectively, in an MC4100 background (Table 1).

\section{Increased P2 and P3 activity on transition from exponential growth to stationary phase}

Both P2 in front of surE and P3 in front of $p c m$ could be significantly induced in a growth-phase-dependent way when CL415-2 or CL415-3 cells were grown in rich medium (LB) (Fig. 2a). Expression from either P2 or P3 was low during early exponential phase (about 30-80 Miller units) but was induced about twofold in midexponential phase. As shown in Fig. 2(a), the level of expression continued to increase about 15 -fold from P2 (about 800-1000 Miller units) and about 12-fold (about 550-700 Miller units) from P3 when the cells reached stationary phase. The level of expression of the P2 operon fusion was consistently slightly higher than that of the P3 operon fusion when cells reached the transition from late exponential to early stationary phase.

Interestingly, when cells were cultured in minimal medium (M9), the maximum induction of activity in stationary-phase cells from $\mathrm{P} 2$ was reduced to about 350 Miller units and that from P3 to about 500 Miller units (Fig. 2b). However, the saturated cell density in minimal medium was lower than that in LB. The maximum $\beta$ galactosidase activity in cells in minimal medium was the same as in cells in $\mathrm{LB}$ at similar $\mathrm{OD}_{600}$. In minimal medium, P3 became a stronger promoter than P2. These results might reflect different requirements of the $p \mathrm{~cm}$ and surE gene products under different nutritional conditions.

\section{The katF/rpoS gene is not required for the induction of $\mathrm{P} 2$ and $\mathrm{P3}$}

In prokaryotes specific $\sigma$ factors play critical roles in the induction of sets of genes required under certain specific growth conditions. A $\sigma$ factor, $\sigma^{\mathrm{s}}$, has been shown to be a central regulator for stationary-phase survival and is required for the expression of more than 20 genes in early stationary phase (Hengge-Aronis, 1993; Loewen \& Hengge-Aronis, 1994). Since either P2 or P3 can be induced as cells enter stationary phase, it is possible that they could be controlled by $\sigma^{\mathrm{s}}$. We transferred the lacZ fusion constructs to an rpoS strain, RH90 (Lange \& Hengge-Aronis, 1991), and the resulting lysogens were 


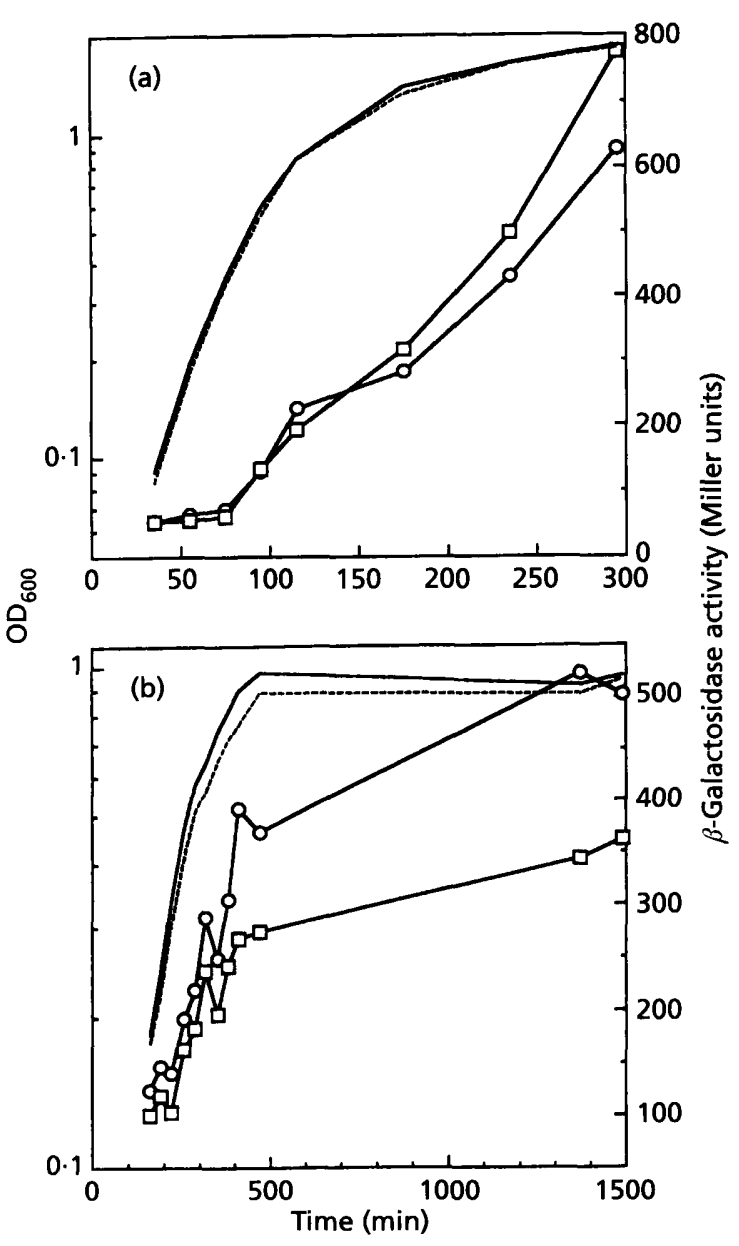

Fig. 2. Expression from $P 2$ and $P 3$ at different growth stages. CL415-2 or CL415-3 cultures grown at $37^{\circ} \mathrm{C}$ in rich medium (a) or minimal medium (b) were inoculated with overnight cultures at a 1:100 dilution. After growth for about $1 \mathrm{~h}$, the cells were further diluted fivefold to assure exponential growth. $\beta$ Galactosidase activities ( $\square, C L 415-2 ; O, C L 415-3)$ are the means of duplicate measurements and similar results were obtained in at least three independent experiments. The growth curves $\left(\mathrm{OD}_{600}\right)$ of CL415-2 (-) and CL415-3 (-- ) are shown.

designated CL415-2R and CL415-3R (Table 1). We could not detect differences in lacZ expression in either construct compared with that in CL415-2 or CL415-3 (Fig. 3). Similar results were obtained for cells grown in minimal medium (data not shown). The results indicate that although $\sigma^{\mathrm{s}}$ plays an essential role in the expression of some stationary-phase-expressed genes, the stationary-phase induction of $s u r E$ or $p \mathrm{~cm}$ promoters is independent of $\sigma^{\mathrm{s}}$.

\section{Effect of spent LB on P2 and P3 induction}

$k a t F$ and $k a t E$ can be induced as cells enter stationary phase and similar induction can be obtained by spent culture supernatant from early stationary-phase cultures (Mulvey et al., 1990). Whether the stationary-phase

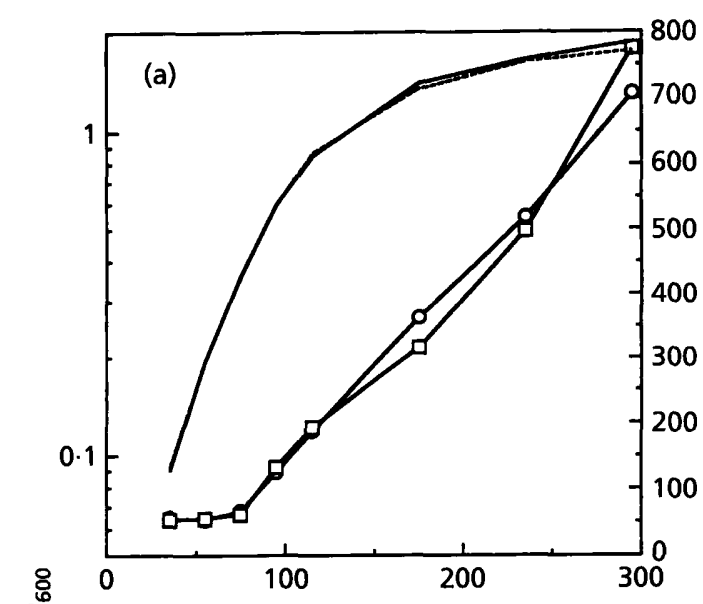

$0^{\circ}$

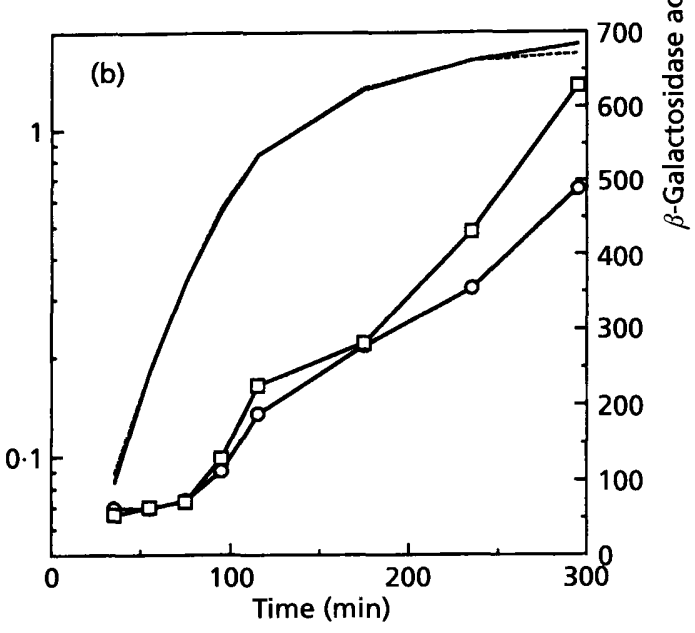

Fig. 3. rpos/katF is not required for the stationary-phase induction of P2 or P3. CL415-2 and its rpoS counterpart CL415-2R (a), and CL415-3 and its rpoS counterpart CL415-3R (b) were cultured in LB as described in the legend to Fig. 2. $\beta$ Galactosidase activities are the means of duplicate measurements and similar results were obtained in two independent experiments. (a) $\beta$-Galactosidase activities: $\square$, CL415-2; O, CL415-2R. Growth curves: - CL415-2; ---, CL415-2R. (b) $\beta$-Galactosidase activities: $\square, C L 415-3 ; O$, CL415-3R. Growth curves: —, CL415-3; - - -, CL415-3R.

induction of P2 or P3 described above is caused by excreted products as cells enter stationary phase was investigated. Spent LB media from early $\left(\mathrm{OD}_{600}\right.$ about $1 \cdot 3$ ) or late stationary-phase (overnight) cultures were prepared. CL415-2 or CL415-3 cultures in early exponential phase $\left(\mathrm{OD}_{600}\right.$ about 0.3$)$ were split into the spent or fresh LB. Growth and $\beta$-galactosidase activity were then determined every 20-40 min. Comparing the spent LB culture with the control culture at the same $\mathrm{OD}_{600}$, an approximately fivefold induction of $\mathrm{P} 2$ could be observed (Fig. 4a). An approximately $2 \cdot 5$-fold induction could be observed for P3 in the spent stationaryphase medium (Fig. 4b). Spent medium from late stationary phase had a similar induction effect (data not shown). If the CL415-2 or CL415-3 cells were grown to mid-exponential phase $\left(\mathrm{OD}_{600}\right.$ about $\left.0.5-0.6\right)$, the in- 


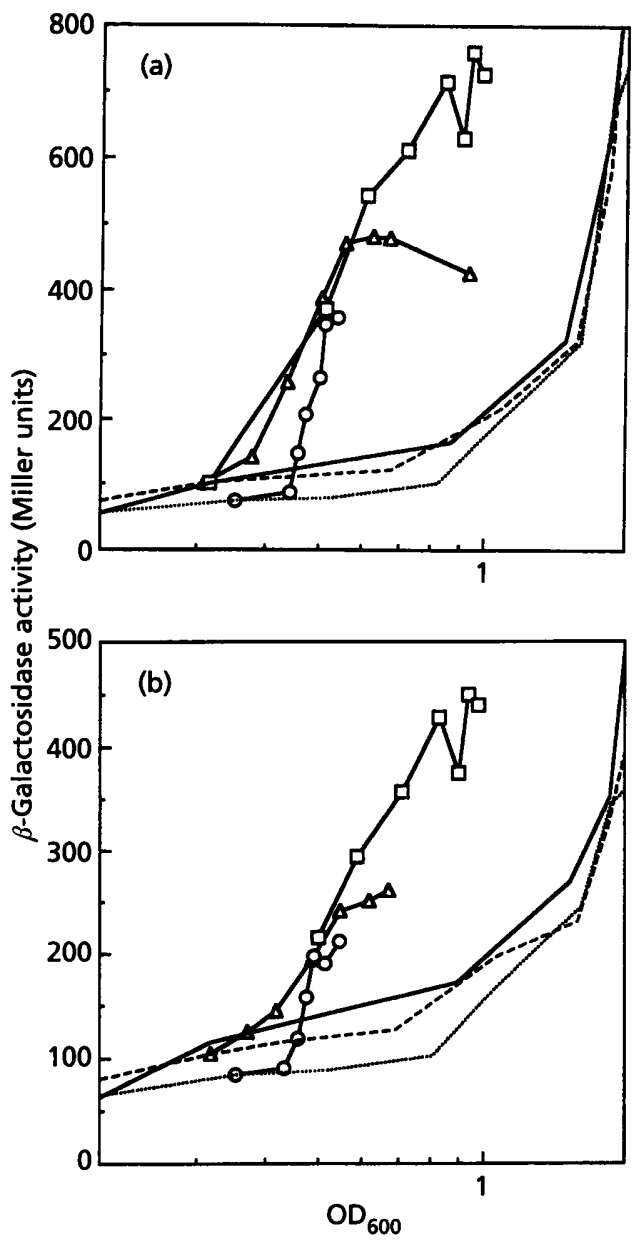

Fig. 4. Effect of spent medium on $P 2$ or $P 3$ induction. Spent LB medium was prepared from an MC4100 culture grown to an $\mathrm{OD}_{600}$ of about 1.3 by filtration through $0.22 \mu \mathrm{m}$ filters. The medium was either boiled for $10 \mathrm{~min}$ or dialysed against SM buffer (20 mM Tris/HCl, pH 7.6, $100 \mathrm{mM} \mathrm{NaCl}, 1 \mathrm{mM} \mathrm{MgSO}_{4}$ $0.1 \mathrm{~g}$ gelatin $\mathrm{I}^{-1}$ ) as described by Mulvey et al. (1990). CL415-2 (a) or CL415-3 cells (b) in exponential phase $\left(O D_{600}\right.$ about $0.3-0.35)$ were divided and resuspended in fresh or spent LB. $\beta$ Galactosidase activities for cells resuspended in spent LB ( $\square$ ), boiled spent LB $(\triangle)$ and dialysed spent LB $(O)$. $\beta$-Galactosidase activities for control cultures (resuspended in fresh LB) of cells resuspended in spent LB (-), boiled spent LB (--) and dialysed spent $L B(\cdots)$.

duction by the spent medium reduced to about twofold for P2 and 1.5-fold for P3 (data not shown). Nevertheless, cell growth appeared to be restricted when the spent medium was used, as the $\mathrm{OD}_{600}$ of the culture increased slowly and could only reach about half of that of the control cultures. We either boiled the spent medium or dialysed it against buffer to analyse the active components responsible for the induction. Interestingly, neither treatment could completely reduce the induction effect of the spent medium, although lower maximum induction was obtained (Fig. 4). Consistent with these results was that some metabolites such as ethanol, acetate, lactate, pyruvate and benzoate at $20 \mathrm{mM}$ could

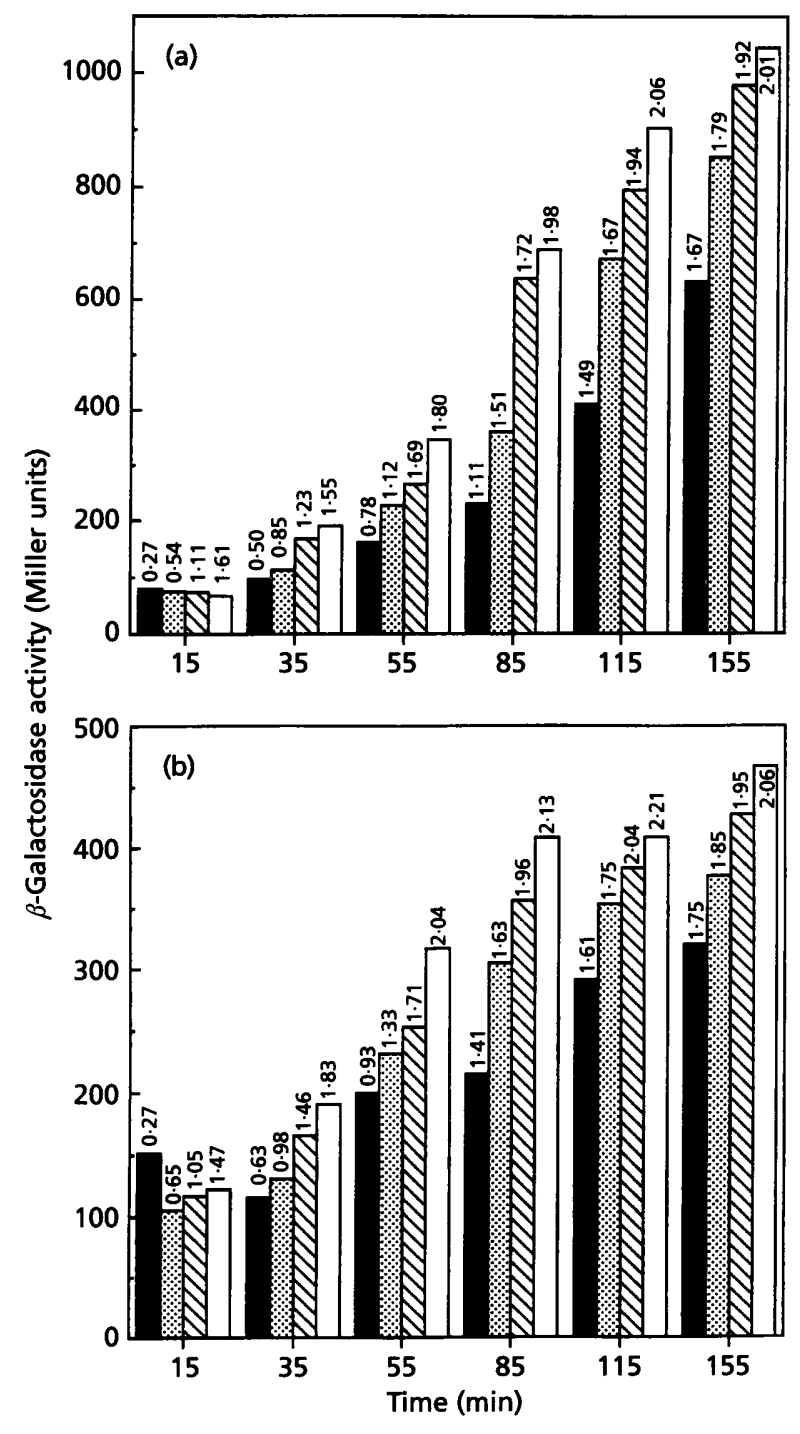

Fig. 5. Effects of the increase in cell density on $P 2$ and $P 3$ induction. CL415-2 cells (a) or CL415-3 cells (b) were harvested in exponential phase $\left(O D_{600}\right.$ about $\left.0.2-0.25\right)$ and resuspended in fresh LB with equal ( $)$, half (圈), quarter $(\mathbb{Q})$ or one-sixth ( $\square$ ) volumes of the original culture. $\beta$-Galactosidase activities are the means of duplicate measurements and similar results were obtained in two independent experiments. The numbers on each column are the $O D_{600}$ values of that culture.

not induce either P2 or P3 (data not shown). It is thus likely that the induction by spent LB was not due to specific heat-stable small metabolites or heat-labile factors but might result from physiological changes in cells when exposed to the spent medium.

\section{Effect of cell density on P2 and P3 induction}

Whether the growth-phase-dependent induction of P2 and P3 was due to the increasing cell density in the culture was also investigated. We pelleted CL415-2 and CL415-3 cells at exponential phase and resuspended 
them in fresh LB with equal, half, quarter, or one-sixth volumes of the original culture. We could not detect any immediate induction from the high cell density cultures after $15 \mathrm{~min}$ growth of the resuspended culture. The high density cultures achieved a high level of induction of $\mathrm{P} 2$ in less time compared with the normal density culture (Fig. 5a). For example, $\beta$-galactosidase activity reached 600 Miller units in the 4-or 6-times concentrated cultures after $85 \mathrm{~min}$ while it took more than $155 \mathrm{~min}$ for the normal cell density culture to reach a similar level of $\beta$-galactosidase activity. A similar induction pattern was obtained for P3 with a lower level of induction (Fig. 5 b). Nevertheless, the high density cultures showed even lower P2 or P3 induction when compared with normal density cultures at the same $\mathrm{OD}_{600}$ values (Fig. 5). Thus, we could not conclude whether the growth-phasedependent induction of P2 or P3 was due to the increasing cell density.

\section{DISCUSSION}

We have demonstrated that not only is the region in front of surE, which was previously proposed to be a potential promoter, a good promoter but also the region in front of $p \mathrm{~cm}$ could be a good promoter. Thus, $p \mathrm{~cm}$ encoding a $\mathrm{Pcm}$ required for stationary-phase survival either can be expressed from P2 (surEp), following surE as in an operon, or can be transcribed independently from the P3 $(p c m p)$ promoter. Interestingly, the transcription level from both promoters during exponential growth could be induced in a growth-dependent way as cells approached stationary phase. This induction could be observed when cells were grown in either rich or minimal medium.

$p c m$ is upstream of the $k a t F / r p o S$ gene encoding the $\sigma$ factor, $\sigma^{\mathrm{s}}$, separated by only one gene $(n l p D$, Ichikawa $e t$ al., 1994). However, the induction of surEp and pcmp for these two essential stationary-phase genes is independent of the product of the rpoS/katF gene that has been shown to be essential for the expression of a few required stationary-phase genes (Hengge-Aronis, 1993; Loewen \& Hengge-Aronis, 1994). This result is consistent with the observation that the presence of extra copies of katF in the pMMkatF3 transformant did not increase the level of Pcm (Fu et al., 1991). At the same time, the specific activity of $\mathrm{Pcm}$ was the same in both the katF wild-type strain (MP180) or katF-deficient strain (UM122) (C. Li, unpublished data). Other promoters such as $o s m C_{p 1}$ (Gordia \& Gutierrez, 1996) and the promoter of the glgCAP operon (Hengge-Aronis \& Fischer, 1992) have been reported to be growth-phaseregulated but $r p o S$-independent. The exact mechanism of the induction has not been elucidated.

Spent medium from early or late stationary-phase cells can induce either P2 or P3. This induction was observed even after boiling or dialysis of the spent medium. It is thus likely that the induction was due to growth-phasedependent physiological changes in the cells rather than secondary metabolites or protein factors excreted to the growth medium, or $\mathrm{pH}$ changes in the medium. An increase in cell density can induce $\beta$-galactosidase activity more rapidly but cannot induce the activity immediately, nor to a higher extent. We observed that in all of the experiments the induction usually occurred 30-60 min after the decline of the culture growth rate. We propose that the continuous reduction of the culture growth rate from exponential to stationary phase might co-relate with the continuous increase in P2 and P3 induction. The larger the reduction in growth rate, the greater the induction observed. Abrupt growth rate changes when cells were shifted to the spent medium or to a smaller volume of growth medium lead to large growth rate changes and thus induced the promoters. In this hypothesis it is the decline in the growth rate, not the slow growth rate that can induce the promoters. The low maximum induction of $\mathrm{P} 2$ and $\mathrm{P} 3$ in cells grown in minimal medium might be due to the slow growth and small growth rate changes as cells approach stationary phase under low nutrient conditions. In bacteria, growth rate changes affect protein synthesis greatly (Bremer \& Dennis, 1987). It is reasonable that the protein-repair methyltransferase could be induced when protein synthesis is decreased with reduced growth rate.

The observed growth-phase-dependent induction was probably not due to the relA genetic background of strain MC4100 used for the lac $Z$ operon fusion studies. We moved the fusions to another $\Delta l a c Z$ strain, MC1000, that was $\mathrm{relA}^{+}$and obtained similar induction results (C. $\mathrm{Li}$, unpublished data).

The similarity of the induction of P2 and P3 indicates that both promoters are controlled by similar factors. P2 appears to be a typical $\sigma^{70}$ promoter with homologous -10 and -35 regions. This has been confirmed by primer extension analysis (Li et al., 1994). However, no sequence homology can be identified between P2 and P3. Further analysis of the cis-elements and trans-acting factors that are responsible for the similar induction of both promoters is important.

The arrangement of the surE-pcm-nlpD-rpoS genes important for stationary-phase survival on the $59 \mathrm{~min}$ region of the $E$. coli chromosome has been proposed to be conserved in Gram-negative bacteria ( $\mathrm{Li}$ et al., 1994; Visick \& Clarke, 1995). The genomes of a Gramnegative bacterium (Haemophilus influenzae, Fleischmann et al., 1995), a Gram-positive bacterium (Mycoplasma genitalium, Fraser et al., 1995) and an Archaeon (Methanococcus jannaschii, Bult et al., 1996) have been completely sequenced. Examination of the arrangement of the genes in these bacteria has revealed interesting information. No $\mathrm{pcm}$ homologue can be identified in M. genitalium, consistent with our previous survey in that methyltransferase activity is absent in Gram-positive bacteria (Li \& Clarke, 1992a). Interestingly, no $\mathrm{pcm}$ homologue can be found in $H$. influenzae while a good homologue of surE can be identified. The hypothetical surE product of $H$. influenzae appeared to be 90 aa shorter at the $N$ terminus. The portion corresponding to the $\mathrm{N}$ terminus of E. coli surE and the P2 region was proposed to be present in a 


\section{$\overline{500 \mathrm{bp}}$}

Escherichia coli 59 min region

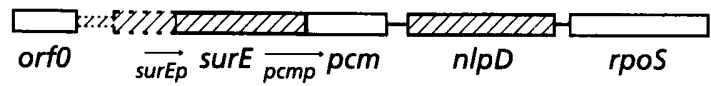

Haemophilus influenzae Rd nt 746600-752000

HI701 surE IPpB $\frac{\text { nIpD }}{\text { muts }}$

Fig. 6. Comparison of the organization of the $59 \mathrm{~min}$ region on the $E$. coli chromosome and the arrangement of genes in the $746600-752000 \mathrm{nt}$ region on the $H$. influenzae genome. ORFs are shown as boxes and the direction of all ORFs is from left to right. ORFs with sequences conserved between the two bacteria are represented by hatching. ORFs at a similar chromosomal position but which are not homologous are represented by white ( $E$. coli) or black ( $H$. influenzae). The nucleotide sequence of the hypothetical protein HI701 of $H$. influenzae is highly conserved (about $55 \%$ identity) compared to the nucleotide sequence of the intragenic region between orfO and surE as well as the $5^{\prime}$ coding region of surE in $E$. coli.

hypothetical protein, HI701, of $H$. influenzae (see Fig. 6). We examined the degree of homology between the E. coli P2 segment from this study and the $H$. influenzae sequence and found $58.5 \%$ identity. The $5^{\prime}$ half of the $\mathrm{P} 3$ region was located in the coding region of surE and thus showed a high degree of homology between both bacteria. No homologous sequence could be found in $H$. influenzae for the $3^{\prime}$ portion of P3 that extends into the $p c m$ coding region of $E$. coli. On the $H$. influenzae chromosome surE is followed by $\operatorname{lp} p B$, a homologue of $E$. coli $n l p D$, and a $m u t S$ gene homologue (encoding a DNA gyrase) (Fig. 6). The arrangement was similar to that observed in a closely related species, $H$. somnus, that has been compared with E. coli (Theisen et al., 1993).

In M. jannaschii, a pcm homologue with $45.6 \%$ amino acid identity can be identified. Putative Pcm activity was observed in another thermophilic Archaeon, Sulfolobus acidocaldarius, using ovalbumin as the methyl-accepting substrate ( $\mathrm{Li}, 1993)$. However, no activation could be detected when L-isoaspartyl-containing peptides were included in the reaction. It has not been determined whether the $S$. acidocaldarius enzyme works only on proteins but not on peptide methyl-accepting substrates, or whether the exogenous peptide substrates were rapidly degraded by the bacterial extract and thus could not be methylated by the putative methyltransferase. Nevertheless, since a highly conserved $p c m$ gene is present in $M$. jannaschii, it is likely that the enzyme is conserved in the Archaea and might play some role in their survival. A surE homologue (34.4\% identity) can also be identified in the M. jannaschii genome but is far separated from $p c m$.

Recently, using nucleotide sequence comparison analysis, the presence of $p \mathrm{~cm}$ has been proposed in Pseudomonas aeruginosa (Tanaka \& Takahashi, 1994) and Thermotoga maritima (Swanson et al., 1996). However, both sequences lack the upstream region of $p c m$ and thus are insufficient to determine if the $s u r E-p c m$ operon arrangement is present in these bacteria. As shown in $H$. influenzae, pcm could be totally missing. Our lacZ operon fusion results indicate that in E. coli, although the surE and $p c m$ gene overlap by $4 \mathrm{bp}$, and as well as the surE promoter that is responsible for the bicistronic expression of surE and $p c m$, a strong promoter is located directly upstream of $p c m(\mathrm{P} 3)$ and the regulation of both genes can be separated.

The level of induction of both $p c m p$ and surEp from exponential to stationary phase is approximately tenfold. These results can be compared with the 1.7-fold increase in Pcm activity of strain MC1000 cells from exponential to stationary phase when grown in LB ( $\mathrm{Li} \&$ Clarke, 1992b). It is very likely that post-transcriptional regulation might be important for the expression of pcm.

\section{ACKNOWLEDGEMENTS}

We thank Dr Robert Simons (University of California, Los Angeles) for providing $\lambda$ RS45 and Dr Regine Hengge-Aronis (University of Konstanz) for providing RH90. We appreciate Hung-Chih Kuo for help in constructing some of the operon fusion plasmids and $\mathrm{Yu}$-Ti Fan for help in assaying the operon fusion plasmids. The work was supported by grant NSC84-2331-B-040-012 from the National Science Council of the Republic of China and CSMC 83-NS-A-022 and CSMC 83NS-A-023 from Chung Shan Medical College to C.L.

\section{REFERENCES}

Bremer, H. \& Dennis, P.P. (1987). Modulation of chemical composition and other parameters of the cell by growth rate. In Escherichia coli and Salmonella typhimurium: Cellular and Molecular Biology, pp. 1527-1542. Edited by F. C. Neidhardt, J. L. Ingraham, K. Brooks Low, B. Magasanik, M. Schaechter \& H. E. Umbarger. Washington, DC: American Society for Microbiology.

Brennan, T. V., Anderson, J. W., Jia, Z., Waygood, E. B. \& Clarke, S. (1994). Repair of spontaneously deamidated HPr phosphocarrier protein catalyzed by the L-isoaspartate-(D-aspartate) $O$ methyltransferase. J Biol Chem 269, 24586-24595.

Bult, C. J., White, O., Olsen, G. J. and 37 other authors (1996). Complete genome sequence of the methanogenic archaeon, Methanococcus jannaschii. Science 273, 1058-1073.

Clarke, S. (1985). Protein carboxyl methyltransferases: Two distinct classes. Annu Rev Biochem 54, 479-506.

Fleischmann, R. D., Adams, M. D., White, O. and 37 other authors (1995). Whole-genome random sequencing and assembly of Haemophilus influenzae Rd. Science 269, 496-512.

Fraser, C. M., Gocayne, J. D., White, O. and 26 other authors (1995). The minimal gene complement of Mycoplasma genitalium. Science 270, 397-403.

Fu, J., Ding, L. \& Clarke, S. (1991). Purification, gene cloning, and sequence analysis of an L-isoaspartyl protein carboxyl methyltransferase from Escherichia coli. J Biol Chem 266, 14562-14572.

Gordia, S. \& Gutierrez, C. (1996). Growth-phase-dependent expression of the osmotically inducible gene osmC of Escherichia coli K-12. Mol Microbiol 19, 729-736.

Harding, J., Beswick, H. T., Ajiboye, R., Huby, R., Blakytny, R. \& Rixon, K. C. (1989). Nonenzymatic post-translational modification of proteins in aging. A review. Mech Ageing Dev 50, 7-16. 
Hengge-Aronis, R. (1993). Survival of hunger and stress: The role of $r p o S$ in early stationary phase gene regulation in E. coli. Cell 72, 165-168.

Hengge-Aronis, R. \& Fischer, V. (1992). Identification and molecular analysis of $g l g S$, a novel growth-phase-regulated and rpoS-dependent gene involved in glycogen synthesis in Escherichia coli. Mol Microbiol 6, 1877-1886.

Ichikawa, J. K., Li, C., Fu, J. \& Clarke, S. (1994). A gene at 59 minutes on the Escherichia coli chromosome encodes a lipoprotein with unusual amino acid repeat sequences. J Bacteriol 176, 1630-1638.

Ingrosso, D., Fowler, A. V., Bleibaum, J. \& Clarke, S. (1989). Sequence of the D-aspartyl/L-isoaspartyl protein methyltransferase from human erythrocytes. $J$ Biol Chem 264, 20131-20139.

Johnson, B. A., Murray, E. D., Jr, Clarke, S., Glass, D. B. \& Aswad, D. W. (1987). Protein carboxyl methyltransferase facilitates conversion of atypical L-isoaspartyl peptides to normal L-aspartyl peptides. J Biol Chem 262, 5622-5629.

Johnson, B. A., Ngo, S. Q. \& Aswad, D. W. (1991). Widespread phylogenetic distribution of a protein methyltransferase that modifies L-isoaspartyl residues. Biochem Int 24, 481-487.

Kagan, R. M. \& Clarke, S. (1995). Protein L-isoaspartyl methyltransferase from the nematode Caenorhabditis elegans: genomic structure and substrate specificity. Biochemistry 34, 10794-10806.

Kolter, R., Siegele, D. A. \& Tormo, A. (1993). The stationary phase of the bacterial life cycle. Annu Rev Microbiol 47, 855-874.

Lange, R. \& Hengge-Aronis, R. (1991). Identification of a central regulator of stationary-phase gene expression in Escherichia coli. Mol Microbiol 5, 49-59.

$\mathrm{Li}, \mathrm{C}$. (1993). The physiological functions of the L-isoaspartyl protein methyltransferase and related proteins in bacteria. $\mathrm{PhD}$ thesis, Department of Chemistry and Biochemistry, University of California, Los Angeles, CA, USA.

Li, C. \& Clarke, S. (1992a). Distribution of an L-isoaspartyl protein methyltransferase in eubacteria. J Bacteriol 174, 355-361.

Li, C. \& Clarke, S. (1992b). A protein methyltransferase specific for altered aspartyl residues is important in Escherichia coli stationary-phase survival and heat-shock resistance. Proc Natl Acad Sci USA 89, 9885-9889.

Li, C., Ichikawa, J. K., Ravetto, J. J., Kuo, H.-C., Fu, J. C. \& Clarke, S. (1994). A new gene involved in stationary-phase survival located at 59 minutes on the Escherichia coli chromosome. $J$ Bacteriol 176, 6015-6022.

Loewen, P. C. \& Hengge-Aronis, R. (1994). The role of the sigma factor $\sigma^{\mathrm{s}}(\mathrm{KatF})$ in bacterial global regulation. Annu Rev Microbiol 48, 53-80.

Matin, A., Auger, E. A., Blum, P. H. \& Schultz, J. E. (1989). Genetic basis of starvation survival in nondifferentiating bacteria. Annu Rev Microbiol 43, 293-316.
McFadden, P. N. \& Clarke, S. (1982). Methylation at D-aspartyl residues in erythrocytes: possible step in the repair of aged membrane proteins. Proc Natl Acad Sci USA 79, 2460-2464.

McFadden, P. N. \& Clarke, S. (1987). Conversion of isoaspartyl peptides to normal peptides: implications for the cellular repair of damaged proteins. Proc Natl Acad Sci USA 84, 2595-2599.

Miller, J. H. (1992). A Short Course in Bacterial Genetics: a Laboratory Manual and Handbook for Escherichia coli and Related Bacteria. Cold Spring Harbor, NY: Cold Spring Harbor Laboratory.

Mudgett, M. B. \& Clarke, S. (1993). Characterization of plant Lisoaspartyl methyltransferases that may be involved in seed survival: Purification, cloning, and sequence analysis of the wheat germ enzyme. Biochemistry 32, 11100-11111.

Mulvey, M. R., Switala, J., Borys, A. \& Loewen, P. (1990). Regulation of transcription of katE and katF in Escherichia coli. $J$ Bacteriol 172, 6713-6720.

O'Connor, C. M. \& Clarke, S. (1985). Specific recognition of altered polypeptides by widely distributed methyltransferases. Biochem Biophys Res Commun 132, 1144-1150.

Roszak, D. B. \& Colwell, R. R. (1987). Survival strategies of bacteria in the natural environment. Microbiol Rev 51, 365-379.

Siegele, D. A. \& Kolter, R. (1992). Life after log. J Bacteriol 174, 345-348.

Simons, R. W., Houman, F. \& Kleckner, N. (1987). Improved single and multicopy lac-based cloning vectors for protein and operon fusions. Gene 53, 85-96.

Stadtman, E. R. (1988). Protein modification in aging. J Gerontol 43, B112-B120.

Swanson, R. V., Sanna, M. G. \& Simon, M. I. (1996). Thermostable chemotaxis proteins from the hyperthermophilic bacterium Thermotoga maritima. J Bacteriol 178, 484-489.

Tanaka, K. \& Takahashi, H. (1994). Cloning, analysis and expression of an rpoS homologue gene from Pseudomonas aeruginosa PAO1. Gene 150, 81-85.

Theisen, M., Rioux, C. R. \& Potter, A. A. (1993). Molecular cloning, nucleotide sequence, and characterization of $l p p B$, encoding an antigenic 40-kilodalton lipoprotein of Haemophilus somnus. Infect Immun 61, 1793-1798.

Visick, J. E. \& Clarke, S. (1995). Repair, refold, recycle: how bacteria can deal with spontaneous and environmental damage to proteins. Mol Microbiol 16, 835-845.

Weichart, D., Lange, R., Henneberg, N. \& Hengge-Aronis, R. (1993). Identification and characterization of stationary phaseinducible genes in Escherichia coli. Mol Microbiol 10, 407-420.

Received 10 April 1997; revised 15 July 1997; accepted 8 August 1997. 